\section{CURRÍCULO E PRÁTICA PEDAGÓGICA NO COTIDIANO ESCOLAR DA EDUCAÇÃO FÍSICA: UMA REVISÃO EM PERIÓDICOS NACIONAIS}

\author{
PHYSICAL EDUCATION CURRICULUM AND PEDAGOGICAL PRACTICE \\ IN DAILY SCHOOL LIFE: A REVIEW IN BRAZILIAN JOURNALS
}

\section{CURRÍCULO Y PRÁCTICA PEDAGÓGICA EN EL COTIDIANO ESCOLAR DE LA EDUCACIÓN FÍSICA: UNA REVISIÓN EN PERIÓDICOS BRASILEÑOS}

\author{
Juliana de Oliveira Freire*, Aldecilene Cerqueira Barreto*, \\ Ingrid Dittrich Wiggers*
}

\begin{abstract}
Resumo: No presente artigo analisamos as articulações entre currículo e prática pedagógica da Educação Física no cotidiano escolar do Ensino Fundamental. Para tanto, realizamos um estudo de revisão sistemática em periódicos do campo da Educação Física brasileira, resultando numa seleção de 13 artigos entre 2008 e 2017. Concluímos que os Parâmetros Curriculares Nacionais, os currículos dos estados e municípios e os projetos político-pedagógicos subsidiam o planejamento e a prática pedagógica, sem interferir na autonomia do professor. Os estudos apresentados indicam a sistematização dos conteúdos como elemento preponderante para a legitimação da Educação Física. As elaborações e análises de propostas de ensino repercutiram a hegemonia do esporte como conteúdo, porém percebemos a tentativa de ampliação do seu entendimento como fenômeno cultural. Sugerimos pesquisas que problematizem a prática pedagógica no cotidiano escolar, que subsidiem reformulações e produções curriculares na formação inicial e continuada, em colaboração entre escola e universidade.
\end{abstract}

Keywords: Systematic Review. Curriculum. Physical Education. Elementary School.

Palabras clave: Revisión Sistemática. Currículo. Educación Física. Educación Primaria.
Abstract: This article analyzes relations between Physical Education curriculum and teacher practice in Brazilian Elementary School. We conducted a systematic review of Brazilian Physical Education journals, resulting in a selection of 13 articles published between 2008 and 2017. We found that the National Curricular Parameters, state and municipal curricula, and political-pedagogical projects inform educational planning and practice without interfering with teachers' autonomy. The studies point to content systematization as a predominant element to legitimate Physical Education. The design and analysis of teaching proposals highlighted the hegemony of sports as a content; however, we found attempts to increase its understanding as a cultural phenomenon. We suggest research discussing educational practice in school, informing curriculum review and production in initial and in-service teacher training, conducted jointly between school and university.

Resumen: En el presente artículo analizamos las relaciones entre currículo y práctica pedagógica de la Educación Física en el cotidiano escolar de la Enseñanza Básica. Para ello, realizamos un estudio de revisión sistemática en periódicos del campo de la Educación Física brasileña, que resultó en una selección de 13 artículos entre 2008 y 2017. Concluimos que los Parámetros Curriculares Nacionales, los currículos de los estados y municipios y los proyectos político-pedagógicos amparan los planes y la práctica pedagógica, sin interferir en la autonomía del profesor. Los estudios presentados indican la sistematización de los contenidos como elemento preponderante para la legitimación de la Educación Física. Las discusiones y análisis de propuestas de enseñanza reflejan la hegemonía del deporte como contenido, aunque percibimos el intento de ampliar su comprensión como fenómeno cultural. Sugerimos investigaciones que problematicen la práctica pedagógica en el cotidiano escolar, que amparen reformulaciones y producciones curriculares en la formación inicial y continuada, en colaboración entre escuela y universidad.
*Universidade de Brasília. Brasília DF, Brasil.

E-mail:

juliana2609@gmail.com; aldecilene@hotmail.com; ingridwiggers@gmail.com.

Recebido em: 25-06-2019 Aprovado em: 11-02-2020 Publicado em: 24-03-2020 


\section{INTRODUÇÃO}

Atualmente observamos o uso de artigos científicos como fontes primárias em pesquisas acadêmicas, de modo a gerar sínteses a partir de interpretações dos dados. Nesse sentido, os estudos de revisão sistemática a respeito de um tema ultrapassam a organização e o resumo dos achados de pesquisas, mas produzem novas categorias de análise e até mesmo outros modelos conceituais e teorias que se tornam bases para trabalhos futuros (RAPLEY; REES, 2018).

Nessa direção, a presente pesquisa tem como escopo as articulações entre o currículo e a prática pedagógica da educação física no cotidiano escolar. O conceito de currículo no âmbito educacional não é unânime entre os pesquisadores, todavia, compreendemos o currículo como as diretrizes educacionais que têm a função de orientar o trabalho docente no cotidiano escolar. Nesse sentido, corroboramos Sacristán (2000, p. 202), ao afirmar que "o currículo se expressa em usos práticos, que além disso, têm outros determinantes e uma história". Para o autor, o currículo apresenta vários níveis, dentre os quais destacamos o currículo na ação. Quanto à prática pedagógica, Libâneo (2013) evidencia sua vinculação aos aspectos didáticos que mediam os objetivos e conteúdos na escola. Logo, no âmbito deste artigo enfocamos a articulação entre o currículo e a prática pedagógica dos professores.

Estudos que utilizam como método a revisão sistemática no campo da educação física escolar apontam para a necessidade de pesquisas que abordem a temática currículo. Dentre eles, referenciamos Bracht et al. (2011), que objetivaram mapear a produção do conhecimento sobre a educação física escolar no Brasil entre 1980 a 2010. Os autores evidenciaram que 43, ou 6,6\% dos 647 artigos analisados entre 1980 e 2010, se referiam ao tema currículo e organização. Semelhantemente, Wiggers et al. (2015) discutiram a produção acadêmico-científica na educação física escolar brasileira entre 2006 e 2012 e evidenciaram que houve um crescimento das pesquisas nesse campo. Todavia, 24 dos 438 artigos encontrados referem-se à temática currículo e organização, que corresponde a $5,61 \%$ do total das pesquisas.

Estas investigações corroboram os resultados das pesquisas realizadas no âmbito internacional. Kulinna et al. (2009) investigaram os temas das pesquisas no campo da educação física em língua inglesa em uma década e concluíram que, dos 1.819 artigos, 19,24\% enfocaram o currículo. Do mesmo modo, Kirk (2010) analisou as tendências das pesquisas em educação física na Europa e destacou a necessidade de estudos com a temática currículo e conhecimento. $\mathrm{O}$ autor concluiu que no campo da educação física "ainda temos alguma distância para percorrer no desenvolvimento de conceitos e teorias que nos permitam considerar as relações entre currículo, ensino e aprendizagem" (KIRK, 2010, p. 32). Tal constatação sugere a necessidade de investigar as relações entre a teoria curricular e a prática pedagógica.

Ao realizarem um estudo de revisão especificamente sobre o tema currículo e educação física escolar, Boscatto e Darido (2017) apontam que 0,93\% dos artigos publicados em 2015 abordavam a temática currículo. Em adição, Tavares, Wittizorecki e Molina Neto (2018), ao examinarem o espaço da educação física nos currículos dos anos finais do Ensino Fundamental, explicitam que há uma pluralidade de compreensões acerca de sua função na escola e no currículo, em um debate que perpassa as definições de conteúdos legítimos e a hegemonia do esporte. 
A partir desses apontamentos, reiteramos a relevância do estudo, cujo objetivo consiste em analisar as articulações entre currículo e prática pedagógica da educação física no cotidiano escolar do Ensino Fundamental, por meio de uma revisão sistemática em periódicos do campo da educação física brasileira.

\section{METODOLOGIA}

A pesquisa em tela se caracteriza por uma revisão sistemática, um recurso para a compreensão acerca do objeto de investigação a partir de outras pesquisas, conforme detalhado por Sampaio e Mancini (2007), bem como por Gomes e Caminha (2014). Na primeira etapa da investigação foram definidos os objetivos e realizado um levantamento nos sites de oito periódicos do campo sociopedagógico da educação física com qualis A2 a B2 (quadriênio 2013-2016), os mesmos periódicos investigados por Bracht et al. (2011) ${ }^{1}$ e Wiggers et al. (2015). A partir do descritor currículo ${ }^{2}$ no título ou no resumo, o resultado foi de 119 artigos entre os anos 2008 e 2017 (Tabela 1). Ressaltamos que esse critério foi utilizado a fim de abranger artigos que apresentassem a temática currículo como objeto central.

$\mathrm{Na}$ segunda etapa, excluímos artigos que tratavam da formação inicial, continuada ou de pesquisas realizadas no Ensino Médio, que discutiam dificuldades da prática pedagógica, apropriações de teorias ou abordagens educacionais, além de pesquisas teóricas como revisões de literatura, análises documentais ou ensaios. Assim, permaneceram no levantamento as pesquisas empíricas sobre currículo e prática pedagógica realizadas com professores em escolas de Ensino Fundamental e que versavam sobre o currículo em diferentes âmbitos como Parâmetros Curriculares Nacionais (PCN) (BRASIL, 1998), currículos dos estados ou municípios, projetos político-pedagógicos (PPP) ou que apresentavam elaborações de propostas de ensino.

Tabela 1 - Quantidade de artigos por periódicos entre os anos 2008 e 2017

\begin{tabular}{lccc}
\hline \multicolumn{1}{c}{ Periódico } & $\begin{array}{c}\text { Qualis na } \\
\text { educação } \\
\text { física }\end{array}$ & $\begin{array}{c}\text { Quantidade } \\
\text { de artigos } \\
\text { 1a }^{\text {etapa }}\end{array}$ & $\begin{array}{c}\text { Quantidade } \\
\text { de artigos } \\
\text { 2 }^{\text {a }} \text { etapa }\end{array}$ \\
\hline Motrivivência - UFSC & B2 & 28 & 1 \\
Motriz (Revista de Educação Física) - UNESP & B1 & 2 & 0 \\
Movimento - UFRGS & $\mathrm{A} 2$ & 22 & 5 \\
Pensar a Prática - UFG & $\mathrm{B} 2$ & 28 & 3 \\
RBCE - Revista Brasileira de Ciências do Esporte & $\mathrm{B} 1$ & 6 & 1 \\
RBCM - Revista Brasileira de Ciência e Movimento & $\mathrm{B} 2$ & 2 & 0 \\
RBEFE (Revista Brasileira de Educação Física e Esporte) - USP & $\mathrm{B} 1$ & 23 & 3 \\
Journal of Physical Education - UEM & $\mathrm{B} 1$ & 8 & 0 \\
\hline Total & & 119 & 13 \\
\hline
\end{tabular}

Fonte: Os autores.

Com base nos critérios de exclusão e inclusão mencionados, foram selecionados 13 artigos. Em seguida, os artigos foram inseridos no Atlas.ti - software 
que auxilia a análise qualitativa de dados (SCALES, 2013). Este programa permite que o pesquisador estabeleça códigos a partir das marcações durante a leitura dos textos. Cabe destacar que esses códigos são criados livremente e podem ser inseridos ou excluídos a qualquer momento. Desse modo, foram estabelecidos nexos entre essas informações que auxiliaram na definição dos eixos temáticos e na análise e discussão dos dados.

\section{ANÁLISE E DISCUSSÃO}

Os artigos foram organizados em três eixos temáticos de acordo com seus objetivos. O primeiro, apropriações de currículos no cotidiano escolar, representa pesquisas que discutiram como os professores tratam, percebem e interagem com os currículos em seus respectivos estados ou municípios. O segundo eixo, PCN e PPP no cotidiano escolar, aborda o entendimento dos professores de educação física sobre esses documentos, uma vez que o PPP representa "a própria organização do trabalho pedagógico da escola" (VEIGA, 2008, p. 22). Outro aspecto que emergiu das discussões foi o tema elaborações e análises de propostas de ensino, apresentado na terceira parte da análise. A seguir, destacamos em cada eixo temático os autores dos artigos em ordem cronológica crescente da publicação, os respectivos objetivos, níveis de ensino e estados onde ocorreram as pesquisas.

\subsection{APROPRIAÇÕES DE CURRÍCULOS NO COTIDIANO ESCOLAR}

As pesquisas apresentadas neste eixo temático objetivaram discutir a articulação entre a prática pedagógica e os currículos. Ocorreram com professores da Educação Infantil e do Ensino Fundamental, envolvendo os estados da Bahia, de São Paulo e dos municípios de Barueri-SP e Camaragibe-PE, respectivamente (Quadro 1).

Quadro 1 - Autores, objetivos, níveis da educação e estados das pesquisas

\begin{tabular}{|c|c|c|c|}
\hline $\begin{array}{l}\text { Autores } \\
\text { (ano) }\end{array}$ & Objetivos & $\begin{array}{l}\text { Níveis da } \\
\text { educação }\end{array}$ & Estados \\
\hline $\begin{array}{l}\text { Alencar e } \\
\text { Lavoura } \\
(2012)\end{array}$ & $\begin{array}{c}\text { Investigar o trato com o conhecimento na educação } \\
\text { física escolar possibilitando proposituras acerca } \\
\text { da construção de referenciais curriculares para a } \\
\text { prática pedagógica no estado da Bahia. }\end{array}$ & $\begin{array}{c}\text { Educação } \\
\text { Básica (não } \\
\text { especificaram) }\end{array}$ & BA \\
\hline $\begin{array}{c}\text { Rocha e } \\
\text { Daolio (2014) }\end{array}$ & $\begin{array}{l}\text { Analisar a forma como uma professora da } \\
\text { Rede Estadual de São Paulo tem lidado com as } \\
\text { orientações teórico-pedagógicas presentes no atual } \\
\text { CEF-SP para a educação física, e construído sua } \\
\text { prática educativa nas aulas. }\end{array}$ & $\begin{array}{l}\text { Anos finais } \\
\text { do Ensino } \\
\text { Fundamental }\end{array}$ & SP \\
\hline $\begin{array}{l}\text { Marani, } \\
\text { Sanches } \\
\text { Neto e Freire } \\
(2017)\end{array}$ & $\begin{array}{c}\text { Conhecer as percepções dos professores de } \\
\text { educação física do município de Barueri/SP sobre o } \\
\text { plano de referência do componente curricular } \\
\text { e sua implementação. }\end{array}$ & $\begin{array}{l}\text { Ensino } \\
\text { Fundamental (não } \\
\text { especificaram) }\end{array}$ & SP \\
\hline $\begin{array}{c}\text { Tenório et al. } \\
(2017)\end{array}$ & $\begin{array}{c}\text { Analisar interações e decisões de professores } \\
\text { diante de uma proposta curricular para educação } \\
\text { física escolar, subsidiada por uma perspectiva } \\
\text { crítico-superadora. }\end{array}$ & $\begin{array}{l}\text { Educação Infantil } \\
\text { e anos iniciais } \\
\text { do Ensino } \\
\text { Fundamental }\end{array}$ & PE \\
\hline
\end{tabular}

Fonte: Dados da pesquisa. 
Rocha e Daolio (2014) analisam as apropriações do currículo estadual de São Paulo por uma professora de educação física, por meio da etnografia. Os autores indicaram a necessidade de estudos que tratem da complexa relação estabelecida entre as implementações curriculares e o cotidiano escolar, que perpassa a formação, compreensão e representação dos professores e estudantes. Além disso, concluem que a professora se apropria e ressignifica a sua prática pedagógica a partir da leitura do currículo do estado e da relação com os estudantes, ou seja, das representações de como deve ser a educação física escolar tradicional e as novas propostas presentes no currículo em voga.

Ainda no estado de São Paulo, Marani, Sanches Neto e Freire (2017) analisaram as percepções dos professores sobre o currículo do município de BarueriSP e discutiram as relações entre o currículo oficial e o real, ou seja, a relação entre o Plano de Referência do município paulista com a prática pedagógica. Apesar de serem quase unânimes (13 dos 14 professores participantes), ao concordarem com a existência do currículo que uniformiza a prática, os professores tecem críticas, sobretudo em relação às concepções adotadas, à repetição dos conteúdos, à supervalorização do esporte, à falta de materiais adequados e às tarefas burocráticas advindas do registro e da avaliação. Por isso, 13 professores também declararam que adaptam o currículo a partir da abordagem da educação física adotada ou de acordo com a realidade dos estudantes.

Na região Nordeste, Alencar e Lavoura (2012) indicam a necessidade de aprofundamento e compreensão teórica por parte dos professores do município de Itabuna-BA, pois os resultados apontam diferenças entre os pressupostos teóricos das Diretrizes Curriculares pautados na perspectiva crítico-superadora e a prática pedagógica. Por meio de observação não participante e entrevistas, os autores tiveram o intuito de compreender as teorias pedagógicas, objeto, objetivos, função social, conteúdos e avaliação que orientavam sua prática, buscando estabelecer nexos entre o currículo e a prática pedagógica. Os autores consideram a necessidade de estabelecer condições objetivas, a fim de que esse documento seja compreendido pelos professores e não apenas "engavetado". Indicam que a mudança do trabalho pedagógico depende de uma "sólida formação teórica a qual possibilite a rigorosidade entre a teoria do conhecimento, a teoria pedagógica e o trabalho educativo realizado nas unidades escolares" (ALENCAR; LAVOURA, 2012, p .171).

Ainda nessa região brasileira, Tenório et al. (2017) analisam as apropriações e produções do currículo dos professores de educação física no município de Camaragibe-PE. Com base nas considerações dos professores investigados, reiteram que a organização dos conteúdos nas propostas curriculares organizadas em sequência contribuiria para que as aulas de educação física não fossem atividades desarticuladas e sem objetivos definidos. Os autores concluem que o documento é considerado um importante instrumento para nortear a sistematização do trabalho pedagógico e a definição dos conteúdos. Entretanto, observaram uma lacuna entre os pressupostos teóricos do currículo e a prática pedagógica, apontando a necessidade de uma apropriação crítica do documento, a fim de superar a mera reprodução de gestos motores. 
A partir do exposto, observamos que nas pesquisas realizadas no Nordeste a ênfase foi na compreensão acerca dos pressupostos teóricos, sobretudo da abordagem crítico-superadora (SOARES et al., 1992), incorporados às práticas dos professores. Já as pesquisas paulistas buscaram as percepções dos professores sobre os currículos em suas práticas. A metodologia utilizada pelos autores deste eixo temático - entrevista - permitiu compreender o que foi explicitado pelos próprios professores que atuam no Ensino Fundamental. Além disso, Alencar e Lavoura (2012), bem como Rocha e Daolio (2014) realizaram observações das aulas a fim de confrontar as informações dos professores. Os resultados apontam para diferenças entre os pressupostos teórico-metodológicos dos currículos e as práticas pedagógicas, pois os professores ressignificam essas orientações de acordo com suas realidades, levando em conta a disponibilidade de materiais, conforme o espaço físico disponível e ainda a partir da perspectiva teórica sobre o objeto da educação física.

Consideramos que o currículo subsidia o planejamento do professor e, consequentemente, sua prática pedagógica. Nesse sentido, concordamos com Tardif (2010) ao explicitar que o trabalho docente não é apenas uma aplicação dos saberes acadêmicos e curriculares, mas uma transformação e uma reinterpretação a partir dos conhecimentos dos professores. Por isso, os artigos desse eixo temático explicitam a relevância de considerar as práticas cotidianas dos professores. Assim, corroboramos Boscatto e Darido (2017, p. 14), ao evidenciarem a necessidade de "aproximar as produções científicas das práticas de ensino dos professores". Com isso, consideramos a escola como um espaço para produção de conhecimento de modo reflexivo e colaborativo.

\subsection{PCN E PPP NO COTIDIANO ESCOLAR}

Neste item as pesquisas discutem a compreensão dos professores acerca da educação física a partir de sua organização legal e pedagógica na escola. Assim como na seção anterior, foram realizadas com professores da Educação Infantil e do Ensino Fundamental. Estes estudos ocorreram em Pelotas-RS, Maringá-PR e São Paulo-SP (Quadro 2).

Quadro 2 - Autores, objetivos, níveis da educação e estados das pesquisas

\begin{tabular}{|c|c|c|c|}
\hline $\begin{array}{c}\text { Autores } \\
\text { (ano) }\end{array}$ & Objetivos & $\begin{array}{c}\text { Níveis da } \\
\text { educação }\end{array}$ & Estados \\
\hline $\begin{array}{c}\text { Guimarães } \\
(2008)\end{array}$ & $\begin{array}{c}\text { Compreender como a educação física se constitui como } \\
\text { componente curricular, na hierarquia dos saberes, das } \\
\text { séries iniciais de uma escola da rede municipal de } \\
\text { Pelotas, após o processo de discussão e construção do } \\
\text { Projeto Político-Pedagógico (PPP), do Plano de Estudos } \\
\text { e do Regimento Escolar. }\end{array}$ & $\begin{array}{c}\text { Anos iniciais } \\
\text { do Ensino } \\
\text { Fundamental }\end{array}$ & RS \\
\hline $\begin{array}{c}\text { Gramorelli e } \\
\text { Neira (2009) }\end{array}$ & $\begin{array}{c}\text { Averiguar possíveis apropriações dos pressupostos } \\
\text { teórico-metodológicos contidos nos PCN de educação } \\
\text { física pelos professores atuantes nos anos finais do } \\
\text { Ensino Fundamental. }\end{array}$ & $\begin{array}{c}\text { Anos finais } \\
\text { do Ensino }\end{array}$ & Sundamental \\
\hline
\end{tabular}


Continuação do quadro 2.

\begin{tabular}{|c|c|c|c|}
\hline $\begin{array}{c}\text { Venâncio e } \\
\text { Darido (2012) }\end{array}$ & $\begin{array}{l}\text { Apresentar o entendimento que um grupo de } \\
\text { professoras de educação física que trabalham no Ensino } \\
\text { Fundamental na rede municipal de São Paulo têm a } \\
\text { respeito do significado do PPP no cotidiano escolar. }\end{array}$ & $\begin{array}{l}\text { Anos iniciais } \\
\text { e finais } \\
\text { do Ensino } \\
\text { Fundamental }\end{array}$ & SP \\
\hline $\begin{array}{l}\text { Jardim et al. } \\
\quad(2014)\end{array}$ & $\begin{array}{c}\text { Investigar, por meio de pesquisa descritiva, como } \\
\text { a educação física tem se organizado legal e } \\
\text { pedagogicamente na educação infantil e nas séries } \\
\text { iniciais do Ensino Fundamental de escolas municipais de } \\
\text { Maringá-PR. }\end{array}$ & $\begin{array}{l}\text { Educação } \\
\text { Infantil e } \\
\text { anos iniciais } \\
\text { do Ensino } \\
\text { Fundamental }\end{array}$ & PR \\
\hline $\begin{array}{l}\text { Sousa, } \\
\text { Hunger e } \\
\text { Caramaschi } \\
\quad(2014)\end{array}$ & $\begin{array}{l}\text { Analisar se o conteúdo referente à dança está } \\
\text { discriminado no PPP das Escolas; como se apresenta o } \\
\text { ensino da dança nas aulas de educação física e de Arte; } \\
\text { qual o conhecimento dos professores do conteúdo dança } \\
\text { preconizado nos PCN; qual importância é dada ao ensino } \\
\text { da dança na escola e quais são os seus limites. }\end{array}$ & $\begin{array}{l}\text { Anos iniciais } \\
\text { do Ensino } \\
\text { Fundamental }\end{array}$ & SP \\
\hline
\end{tabular}

Fonte: Dados da pesquisa.

Sobre a atuação nos anos iniciais do Ensino Fundamental, Guimarães (2008) analisa um movimento de construção da política curricular - elaboração do PPP, do plano de estudos e do regimento escolar - em uma escola de Pelotas-RS, por meio de análise documental e observações das reuniões pedagógicas. A autora inferiu que a equipe escolar se apropria dos currículos oficiais e os ressignifica. Nesta direção, ressalta que esse componente curricular passou de uma condição marginal e utilitária a uma posição de destaque, por causa do apoio dos gestores e por meio da participação da professora de educação física no planejamento pedagógico. A pesquisadora evidencia que a organização sem hierarquização dos componentes curriculares favorece o trabalho interdisciplinar nessa escola.

Gramorelli e Neira (2009) consideram os PCN um marco no movimento de reorientação curricular, pois houve uma mudança de paradigma ao ampliar a compreensão acerca dos conteúdos da educação física para além do esporte. Por meio de entrevista com grupo focal, os autores consideram que mesmo não mencionando diretamente a influência dos PCN em seus discursos, os professores internalizaram os pressupostos teórico-metodológicos de inclusão, as dimensões dos conteúdos ${ }^{3}$ e a avaliação processual, contidas nesse documento.

Para Sousa, Hunger e Caramaschi (2014), os PCN também são reconhecidos pelos professores por sua relevância para a organização curricular. Os autores analisaram a compreensão dos docentes de educação física e arte sobre a dança no PPP, por intermédio de questionário. Assim, apontaram o estudo dos PCN como uma possibilidade de contribuir para a organização dos conteúdos de dança e, ainda, para a realização de projetos com objetivos comuns que ultrapassem as apresentações em datas comemorativas. Deste modo, ressaltam as dificuldades dos professores devido à falta de espaços, recursos adequados, entre outras, e concluem que os professores de educação física e arte podem desenvolver trabalhos em conjunto para que o conteúdo da dança amplie seu espaço na escola.

3 Zabala (2007) discute as dimensões do conteúdo como procedimental (saber fazer), atitudinal (como fazer) e conceitual (por que fazer). 
Ainda no estado de São Paulo, Venâncio e Darido (2012) analisaram o entendimento que os professores de educação física do município de Bauru têm do PPP e o destacaram como um instrumento que propicia a participação dos professores e norteia a ação coletiva. Por meio de pesquisa-ação concluíram que as discussões e reflexões foram relevantes e consideram o PPP um instrumento de participação que envolve a comunidade escolar, em um planejamento coletivo e interdisciplinar. Reiteram que "cada professor tem a liberdade de selecionar o que bem entender para compor o rol de conteúdos que são ensinados. Não há consenso, nem interesse coletivo para almejar objetivos comuns" (VENÂNCIO; DARIDO, 2012, p. 100). Destarte, a escolha dos conteúdos recai predominantemente sobre os esportes, todavia, ao permitir o planejamento coletivo, outros temas são inseridos, como: esportes radicais, dança, ginástica, luta e capoeira.

Quanto à organização legal e pedagógica da educação física na Educação Infantil e nos anos iniciais do Ensino Fundamental, Jardim et al. (2014) investigaram professores de escolas públicas de Maringá-PR ${ }^{4}$, por meio de questionários. As autoras evidenciam que a maioria dos professores participaram da elaboração do PPP. Além disso, todos consideram que a educação física está constando no PPP como componente curricular e que há um planejamento de suas ações. Em relação à escolha dos conteúdos, as autoras também apontam que a não sistematização de conteúdos contribui para uma inconsistência no trabalho desenvolvido e para a não legitimidade da educação física. Todavia, consideramos relevante destacar que alguns professores escolhem os seus conteúdos com base nos respectivos PPP.

A partir dessas pesquisas, consideramos que os PCN contribuíram para que os professores se inserissem nas discussões e planejamentos escolares, o que ocasionou um período reflexivo, diferenciando as práticas pedagógicas. Além disso, como os PCN orientam, as políticas curriculares são representadas no cotidiano escolar por meio dos PPP, por isso, sua constante discussão e reelaboração contribuem para os planejamentos específicos, que estão intrinsecamente ligados à definição dos conteúdos. Nessa direção, Venâncio e Darido (2012) e Jardim et al. (2014) assinalaram a relevância da sistematização dos conteúdos como elemento preponderante para a legitimidade da educação física enquanto componente curricular.

Nesse contexto, cabe ressaltar a recente elaboração da Base Nacional Comum Curricular - BNCC (BRASIL, 2017). Trata-se de um conjunto de orientações que estabelece conteúdos e sequência que, obrigatoriamente, deverão ser respeitados em todos os níveis da educação básica brasileira. Este tema foi aprofundado por Neira (2018), que considera que há um distanciamento entre a BNCC e o debate atual do campo da educação física, que se revela frágil, incoerente e inconsistente, pois não deixa claros seus pressupostos teóricos, mas ao destacar as habilidades e conteúdos enfatiza preceitos das teorias tradicionais de currículo. Nessa direção Sampaio e Behmoiras (2018) reiteram suas críticas à organização dos conteúdos na BNCC, mas defendem a progressão curricular a partir do currículo e do PPP da escola, considerando a realidade local e a participação dos estudantes. 


\subsection{ELABORAÇÕES E ANÁLISES DE PROPOSTAS DE ENSINO}

Esta seção destaca pesquisas que tratam da elaboração, discussão e/ou análise de propostas de ensino. Estas foram realizadas com professores dos Anos finais do Ensino Fundamental. Aconteceram no Rio Grande do Sul e em São Paulo, prevalecendo os estudos neste último estado (Quadro 3).

Quadro 3 - Autores, objetivos, níveis da educação e estados das pesquisas

\begin{tabular}{|c|c|c|c|}
\hline $\begin{array}{c}\text { Autores } \\
\text { (ano) }\end{array}$ & Objetivos & $\begin{array}{l}\text { Níveis da } \\
\text { educação }\end{array}$ & Estados \\
\hline $\begin{array}{c}\text { Barroso e } \\
\text { Darido (2010) }\end{array}$ & $\begin{array}{l}\text { Construir, implementar e avaliar uma proposta de ensino } \\
\text { do voleibol nas três dimensões do conteúdo: conceitual, } \\
\text { procedimental e atitudinal, e identificar } \\
\text { as possibilidades e dificuldades do } \\
\text { desenvolvimento desta proposta. }\end{array}$ & $\begin{array}{l}\text { Anos Finais } \\
\text { do Ensino } \\
\text { Fundamental }\end{array}$ & SP \\
\hline $\begin{array}{l}\text { Carlan, } \\
\text { Kunz e } \\
\text { Fensterseifer } \\
\text { (2012) }\end{array}$ & $\begin{array}{l}\text { Compreender a prática pedagógica de um professor } \\
\text { colaborador no trato do conhecimento do esporte na } \\
\text { educação física de } 5^{a} \text { a } 8^{a} \text { séries. }\end{array}$ & $\begin{array}{l}\text { Anos Finais } \\
\text { do Ensino } \\
\text { Fundamental }\end{array}$ & RS \\
\hline $\begin{array}{c}\text { Diniz e Darido } \\
\text { (2015) }\end{array}$ & $\begin{array}{c}\text { Elaborar e avaliar um material didático complementar ao } \\
\text { currículo de educação física do Estado de São Paulo, } \\
\text { sob a forma de um blog educacional, para subsidiar } \\
\text { a atuação pedagógica do professor no conteúdo de } \\
\text { danças folclóricas proposto para o sétimo ano do ensino } \\
\text { fundamental. }\end{array}$ & $\begin{array}{l}\text { Anos Finais } \\
\text { do Ensino } \\
\text { Fundamental }\end{array}$ & SP \\
\hline $\begin{array}{l}\text { Luguetti et al. } \\
\qquad(2015)\end{array}$ & $\begin{array}{c}\text { Analisar e caracterizar o planejamento das práticas } \\
\text { esportivas escolares no ensino fundamental no } \\
\text { município de Santos - SP. }\end{array}$ & $\begin{array}{l}\text { Anos Finais } \\
\text { do Ensino } \\
\text { Fundamental }\end{array}$ & SP \\
\hline
\end{tabular}

Fonte: Dados da pesquisa.

Barroso e Darido (2010) reiteram que o esporte na escola não pode ser compreendido apenas sob o aspecto do desenvolvimento da técnica ou do gesto motor, mas considerando sua historicidade. Por meio da pesquisa-ação, os autores discutiram aspectos correlatos às condições de trabalho do professor, à justificativa para escolha da modalidade voleibol como conteúdo e suas dimensões, à técnica do esporte, às características dos alunos e à participação nas aulas. Concluíram que a partir das discussões os professores se empenharam em realizar as atividades que planejaram, de modo a propiciar a participação e reflexão dos estudantes.

Nesta direção, Carlan, Kunz e Fensterseifer (2012) analisaram a prática pedagógica de um professor do município de ljuí-RS, buscando compreender a teoria a partir da prática. Os autores ratificaram que o professor tem domínio do seu planejamento. Os alunos, por sua vez, depreendem as fases do processo de ensino-aprendizagem do futebol e sua contextualização, considerando seus sentidos e significados. Além disso, indicam como uma experiência exitosa que pode ser replicada para o desenvolvimento do esporte enquanto conteúdo da educação física escolar de modo reflexivo.

Diniz e Darido (2015) elaboraram e avaliaram um material didático complementar ao currículo de educação física com o uso do blog, ferramenta a 
distância via internet. Este material, disponível na plataforma digital, tinha o propósito de auxiliar a prática pedagógica em relação ao conteúdo das danças folclóricas. Os professores foram convidados a realizar aulas práticas e registrá-las por meio de vídeos, buscando reduzir as disparidades entre a teoria e a prática. A metodologia utilizada para avaliar esse recurso pedagógico foi a entrevista. A disponibilização dos vídeos produzidos foi um elemento que contribuiu para melhor compreensão e apreensão do conteúdo dança por parte dos professores.

$\mathrm{Na}$ perspectiva do desenvolvimento da técnica esportiva, que difere da educação física escolar, Luguetti et al. (2015) investigaram o esporte no contraturno escolar. O questionário realizado com 85 professores/treinadores no município de Santos-SP teve como propósito analisar os aspectos teóricos que subsidiavam o planejamento, os objetivos, os modos de avaliação dos estudantes, bem como a relação com o PPP. Os autores indicaram a necessidade de aproximação entre teoria e prática a partir da formação inicial e continuada, para uma articulação das atividades esportivas com o PPP e a educação física escolar.

O esporte é compreendido como um dos conteúdos da educação física, cuja hegemonia se refletiu nos resultados dessas investigações. Esses apontamentos estão em consonância com outras pesquisas, como explicitado por Araújo, Rocha e Bossle (2017), que ao analisar os conteúdos da educação física escolar nos periódicos nacionais, observou que as publicações sobre o esporte foram mais recorrentes do que as pesquisas sobre dança, lutas, ginástica e atividades circenses. Todavia, percebemos que há uma tentativa de ampliação do entendimento sobre o esporte enquanto fenômeno cultural, articulado pedagogicamente aos demais conteúdos escolares e ao PPP.

\section{CONSIDERAÇÕES FINAIS}

O currículo expressa diretrizes fundamentais que orientam o trabalho docente. A partir desse entendimento, buscamos compreender os processos que acontecem na prática pedagógica da educação física articulados ao currículo. De acordo com as pesquisas analisadas, destacamos que os documentos curriculares norteiam a prática pedagógica, contudo, os professores mantêm sua autonomia. Destarte, eles garantem seus modos criativos e particulares, ressignificando o currículo previamente estabelecido, traduzido no currículo na ação.

Os estudos apresentados indicam a sistematização dos conteúdos como fundamental para a legitimação da educação física enquanto componente curricular. As elaborações e análises de propostas de ensino repercutiram a hegemonia do esporte como conteúdo da educação física escolar. Porém evidenciou-se uma tendência que busca ampliar a compreensão do esporte enquanto fenômeno cultural, incorporando preceitos de estudos do campo teórico da educação física contemporânea.

Com base nas análises, depreendemos que são necessárias pesquisas que discutam o currículo na ação nas regiões Norte e Centro-Oeste do Brasil, pois a maior parte das pesquisas ocorreu na região Sudeste, sobretudo no estado de São Paulo, provavelmente por se tratar de uma região que apresenta a maior quantidade de cursos de pós-graduação, conforme apontado por Wiggers et al. (2015). 
Em relação às metodologias das pesquisas empíricas analisadas, a entrevista representou o recurso mais utilizado, combinada ou não com outros métodos como questionário, observação das aulas, análise documental, além de pesquisa-ação com realização de cursos e elaboração de recurso didático via internet. Assim, consideramos coerentes tais métodos, para que se tornasse possível compreender a perspectiva dos professores investigados, enfatizando suas apropriações dos currículos em suas práticas pedagógicas.

Baseados nestas considerações, sugerimos estudos que suscitem a reflexão e o debate sobre os currículos, de modo que possibilitem aos professores se apropriarem desse conteúdo de modo crítico e, assim, ressignificarem suas práticas. Para tanto, destacamos a relevância da formação inicial e continuada, em um intercâmbio entre a escola e a universidade de modo colaborativo. Nesse sentido, indicamos ainda estudos que discutam como a BNCC se incorpora ao cotidiano escolar, além das possíveis alterações em relação aos PCN. Outras possibilidades podem ser investigações que problematizem o trabalho docente e que possam subsidiar reformulações e produções curriculares.

\section{REFERÊNCIAS}

ALENCAR, Yllah Oliveira; LAVOURA, Tiago Nicola. O trato com o conhecimento na Educação Física escolar e a construção de referenciais curriculares no estado da Bahia. Motrivivência, n. 38, p. 159-173, jun. 2012. Disponível em: https://periodicos.ufsc.br/index. php/motrivivencia/article/view/2175-8042.2012v24n38p159. Acesso em: 5 mar. 2018.

ARAÚJO, Samuel Nascimento de; ROCHA, Leandro Oliveira; BOSSLE, Fabiano. Os conteúdos de ensino da Educação Física escolar: um estudo de revisão nos periódicos nacionais da área 21. Motrivivência, v. 29, n. 51, p. 205-221, jul 2017. Disponível em: https://periodicos.ufsc.br/index.php/motrivivencia/article/view/2175-8042.2017v29n51p205. Acesso em: 10 maio 2018.

BARROSO, André Luís Rugiero; DARIDO, Suraya Cristina. Voleibol escolar uma proposta de ensino nas dimensões conceitual procedimental e atitudinal do conteúdo. Revista Brasileira de Educação Física e Esporte, v. 24, n. 2, p. 179-194, abr./jun. 2010. Disponível em: http://www.scielo.br/scielo.php?pid=S1807-55092010000200003\&script=sci abstract\&tlng=pt. Acesso em: 5 mar. 2018.

BOSCATTO, Juliano Daniel; DARIDO, Suraya Cristina. Currículo e Educação Física escolar: análise do estado da arte em periódicos nacionais. Journal of Physical Education, v. 28, p. 1-16, 2017. Disponível em: http://www.scielo.br/scielo.php?script=sci abstract\&pid=S244824552017000100203\&lng=pt\&nrm=iso\&tlng=pt. Acesso em: 5 mar. 2018.

BRACHT, Valter et al. A Educação Física Escolar como tema da produção do conhecimento nos periódicos da área no Brasil (1980-2010): parte I. Movimento, v. 17, n. 2, p. 11-34, abr./ jun. 2011. Disponível em: https://seer.ufrgs.br/Movimento/article/view/19280. Acesso em: 3 mar. 2018.

BRASIL. Ministério da Educação. Base Nacional Comum Curricular: Educação é a base. Brasília, 2017. Disponível em: http://portal.mec.gov.br/index.php?option=com_ docman\&view=download\&alias=79601-anexo-texto-bncc-reexportado-pdf-2\&category slug=dezembro-2017-pdf\&ltemid=30192 Acesso em: 10 set. 19. 
BRASIL. Ministério da Educação. Secretaria de Educação Fundamental. Parâmetros Curriculares Nacionais. Brasília, 1998.

BRASIL. Resolução $n^{\circ} 7$ do Conselho Nacional de Educação. Fixa Diretrizes Curriculares Nacionais para o Ensino Fundamental de 9 (nove) anos. Diário Oficial da União, Brasília, DF, 15 de dez. de 2010, Seção 1, p. 34, 2010.

CARLAN, Paulo; KUNZ, Elenor; FENSTERSEIFER, Paulo Evaldo. O Esporte como conteúdo da educação física escolar: estudo de caso de uma prática pedagógica inovadora. Movimento, v. 18, n. 4, p. 55-75, out./dez. 2012. Disponível em: https://seer.ufrgs.br/ Movimento/article/view/29643. Acesso em: 15 mar. 2018.

DINIZ, Irlla Karla dos Santos; DARIDO, Suraya Cristina. Blog Educacional para o ensino das danças folclóricas a partir do Currículo de educação física do estado de São Paulo. Movimento, v. 21, n. 3, p. 701-716, jul./set. 2015. Disponível em: https://seer.ufrgs.br/ Movimento/article/view/53073. Acesso em: 12 mar. 2018.

GOMES, Isabelle Sena; CAMINHA, Iraquitan de Oliveira. Guia para estudos de revisão sistemática: uma opção metodológica para as Ciências do Movimento Humano.

Movimento, v. 20, n. 1, p. 395-411, jan./mar. 2014. Disponível em: https://seer.ufrgs.br/ Movimento/article/view/41542. Acesso em: 5 mar. 2018.

GRAMORELLI, Lílian Cristina; NEIRA, Marcos Garcia. Dez anos de Parâmetros Curriculares Nacionais a prática da Educação Física na visão dos seus autores. Movimento, v. 15, n. 4, p. 107-126, out./dez. 2009. Disponível em: https://www.seer.ufrgs.br/Movimento/article/ view/6863. Acesso em: 5 mar. 2018.

GUIMARÃES, Márcia Rejane Vieira. Educação física no processo de construção permanente da política curricular. Pensar a Prática, v. 11, n. 2, p. 1-7, 2008. Disponível em: https://www.revistas.ufg.br/fef/article/view/1464/4119. Acesso em: 5 mar. 2018.

JARDIM, Nayara Fernanda Perles et al. A educação física como componente curricular na Educação Infantil e nas Séries Iniciais do Ensino Fundamental. Pensar a Prática, v. 17, n. 4, out./dez. 2014. Disponível em: https://www.revistas.ufg.br/fef/article/view/31250. Acesso em: 5 mar. 2018.

KIRK, David. O porquê de investigar: estado atual e tendências futuras nas pesquisas em Educação Física. Movimento, v. 16, n. 2, p. 11-43, abr./jun. 2010. Disponível em: https:// seer.ufrgs.br/Movimento/article/view/12745. Acesso em: 5 mar. 2018.

KULINNA, Hodges Kulinna et al. A decade of research literature in physical education pedagogy. Journal of Teaching in Physical Education, v. 28, p. 119-140, 2009. Disponível em: https://www.researchgate.net/publication/234764284_A_Decade_of_Research_ Literature in Physical Education Pedagogy. Acesso em: 2 fev. 2018.

LIBÂNEO, José Carlos. Didática. 2. ed. São Paulo: Cortez, 2013.

LUGUETTI, Carla Nascimento et al. O planejamento das práticas esportivas escolares no Ensino Fundamental na cidade de Santos. Revista Brasileira de Ciências do Esporte, v. 37, n. 4, p. 314-322, 2015. Disponível em: http://www.scielo.br/scielo.php?pid=S010132892015000400314\&script=sci_abstract\&tlng=pt. Acesso em: 5 mar. 2018.

MARANI, Lidiane; SANCHES NETO, Luiz.; FREIRE, Elisabete dos Santos. O currículo da educação física na rede municipal de Barueri: as percepções dos professores. Movimento, v. 23, n. 1, p. 249-264, jan./mar. 2017. Disponível em: https://seer.ufrgs.br/Movimento/article/ view/65265. Acesso em: 5 mar. 2018. 
NEIRA, Marcos Garcia. Incoerências e inconsistências da BNCC de Educação Física.

Revista Brasileira de Ciências do Esporte, v. 40, n. 3, p. 215-223, 2018. Disponível em: http://www.scielo.br/pdf/rbce/v40n3/0101-3289-rbce-40-03-0215.pdf. Acesso em: 15 set. 2019.

RAPLEY, Tim; REES, Getihin. Collecting documents as data. In: FLICK, Uwe (org.). The sage handbook of qualitative data collection. London: Sage, 2018. p.378-391.

ROCHA, Robinson Luiz Franco da; DAOLIO, Jocimar. A Prática Pedagógica de Educação Física no Currículo de São Paulo: Espaço de tensão entre o tradicional e o novo. Pensar a Prática, v. 17, n. 2, p. 517-529, jan./mar. 2014. Disponível em: https://www.revistas.ufg.br/ fef/article/view/27458. Acesso em: 5 mar. 2018.

SACRISTÁN, José Gimeno. O Currículo: uma reflexão sobre a prática. 3.ed. Porto Alegre: Artmed, 2000.

SAMPAIO, Juarez Oliveira; BEHMOIRAS, Daniel Cantanhede. A cultura corporal no contexto da educação física escolar. In: VEIGA, IIma Passos Alencastro; SILVA, Edileuza Fernandes da (org.). Ensino Fundamental: da LDB à BNCC. Campinas, SP: Papirus, 2018. p. 141168.

SAMPAIO, Rosana Ferreira; MANCINI, Marisa Cotta. Estudos de revisão sistemática: um guia para síntese criteriosa da evidência científica. Revista Brasileira de Fisioterapia, v. 11, n. 1, p. 83-89, jan./fev. 2007. Disponível em: http://www.scielo.br/scielo.php?script=sci arttext\&pid=S1413-35552007000100013. Acesso em: 5 mar. 2018.

SCALES, Jane. Qualitative analysis of student assignments: a practical look at ATLAS.ti. Reference Services Review, v. 41, n. 1, p. 134-147, 2013. Disponível em: https://www. emeraldinsight.com/doi/abs/10.1108/00907321311300956. Acesso em: 8 maio 2018.

SOARES, Carmen Lucia; TAFFAREL, Celi Nelza Zulke; VARJAL, Elizabeth; CASTELLANI FILHO, Lino; ORTEGA ESCOBAR, Micheli; BRACHT, Valter. Metodologia do ensino de educação física. São Paulo: Cortez, 1992.

SOUSA, Nilza Coqueiro Pires de; HUNGER, Dagmar Aparecida Cynthia França;

CARAMASCHI, Sandro. O ensino da dança na escola na ótica dos professores de educação física e artes. Revista Brasileira de Educação Física e Esporte, v. 28, n. 3, p. 505-520, jul./set. 2014. Disponível em: http://www.revistas.usp.br/rbefe/article/view/86667. Acesso em: 5 mar. 2018.

TARDIF, Maurice. Saberes docentes e formação profissional. 11. ed. Petrópolis: Vozes, 2010.

TAVARES, Natacha da Silva; WITTIZORECKI, Elisandro Schultz,; MOLINA NETO, Vicente. Educação Física nos Anos Finais do Ensino Fundamental, suas formas e seus lugares no currículo escolar: um estudo de revisão. Movimento, v. 24, n. 1, p. 275-290, jan./mar. 2018. Disponível em: https://seer.ufrgs.br/Movimento/article/view/62986. Acesso em: 5 mar. 2018.

TENÓRIO, Kadja Michele Ramos et al. Apropriações e produções curriculares de professores de educação física. Movimento, v. 23, n. 4, p. 1177-1190, out./dez. 2017. Disponível em: https://seer.ufrgs.br/Movimento/article/view/69700. Acesso em: 5 mar. 2018.

VEIGA, Ilma. Passos Alencastro. Projeto político pedagógico: uma construção Coletiva. In: VEIGA, IIma. Passos Alencastro (org.). Projeto Político-pedagógico da escola: uma construção possível. Campinas: Papirus, 2008. p. 11-36. 
VENÂNCIO, Luciana.; DARIDO, Suraya Cristina. A educação física escolar e o projeto político pedagógico: um processo de construção coletiva a partir da pesquisa-ação. Revista Brasileira de Educação Física e Esporte, v. 26, n. 1, p. 97-109, jan./mar. 2012. Disponível em: http://www.scielo.br/scielo.php?script=sci_arttext\&pid=S1807-55092012000100010. Acesso em: 5 mar. 2018.

WIGGERS, I. D. et al. Um Raio-x da produção do conhecimento sobre Educação Física escolar 2006-2012. Movimento, Porto Alegre, v. 21, n. 3, p. 831-845, jul./set. 2015.

ZABALA, A. A prática educativa: como ensinar. Porto Alegre: Artmed, 2007. 